\title{
La recuperación del patio en la arquitectura doméstica mudéjar. Restauraciones en el Albaicín de Granada en los últimos treinta años
}

\author{
Recovery of the courtyard in domestic Mudejar architecture. Restoration \\ work in the Albaicin (Granada, Spain) over the last thirty years
}

\author{
M. L. Gutiérrez Carrillo ${ }^{(*)}$, I. Bestué Cardiel ${ }^{(*)}$, J. C. Molina Gaitán $^{(* *)}$
}

\section{RESUMEN}

El patio, como núcleo central de la casa mudéjar granadina ha sido uno de los elementos que ha sufrido más transformaciones en los procesos de evolución arquitectónica.

La revalorización de estas arquitecturas domésticas a través de su rehabilitación para nuevos o análogos usos respecto a los originales, ha motivado intervenciones de muy diferente índole sobre el elemento centralizador del patio.

A partir del estudio de una muestra significativa de setenta viviendas intervenidas en los últimos treinta años en Granada, analizamos las metodologías de actuación, los criterios definidos y los procesos constructivos de restauración y conservación. De este modo se obtiene una visión de conjunto diacrónica de la evolución del proceso restaurador en Granada sobre esta tipología, que abarca desde las reinterpretaciones en estilo en las etapas más tempranas a los criterios de autenticidad y de reinterpretación arquitectónica desde la contemporaneidad para las actuaciones más actuales.

Palabras clave: Patio; arquitectura doméstica mudéjar; rehabilitación; procesos de intervención.

\section{ABSTRACT}

Once the focal point of Mudejar houses in Granada, the courtyard is one of the elements that have undergone most transformation in the process of architectural evolution.

The renewed use of these domestic structures as a result of refurbishment for new or similar purposes with respect to their original use has inspired a wide range of very different interventions on the unifying element of the courtyard.

In a study of a large sample of seventy homes which have been subject to restoration over the last thirty years in Granada, we analysed the intervention methodologies employed, the criteria defined and the construction processes of restoration and conservation.

This has yielded a historical perspective of the sample in terms of how the restoration of Mudejar courtyards has evolved in Granada, encompassing stylistic reinterpretations in the earliest stages to the contemporary criteria of authenticity and architectural reinterpretation in recent interventions.

Keywords: Courtyard; domestic Mudejar architecture; refurbishment; process of restoration.

(*) Universidad de Granada (España).

${ }^{(* *)}$ Universidad Politécnica de Cartagena. Murcia (España).

Persona de contacto/Corresponding author: mlgutier@ugr.es (M. L. Gutiérrez Carrillo).

Cómo citar este artículo/Citation: Gutiérrez Carrillo, M. L., Bestué Cardiel, I., Molina Gaitán, J. C. (2016). La recuperación del patio en la arquitectura doméstica mudéjar. Restauraciones en el Albaicín de Granada en los últimos treinta años. Informes de la Construcción, 68(542): e152, doi: http://dx.doi.org/10.3989/ic.15.087.

Licencia / License: Salvo indicación contraria, todos los contenidos de la edición electrónica de Informes de la Construcción se distribuyen bajo una licencia de uso y distribución Creative Commons Attribution License (CC BY) Spain 3.o. 


\section{INTRODUCCIÓN}

El patio, como elemento central de la arquitectura doméstica es esencial en la tradición mediterránea. La arquitectura nazarí marca el último periodo medieval en Andalucía oriental, siendo el patio su eje compositivo. Su pervivencia y evolución en el arte mudéjar, conceden un especial protagonismo a su presencia y función en las construcciones domésticas, actuando como espacio organizador de la arquitectura y centro de relaciones sociales. Asimismo, sus características físicas y de diseño favorecen los patrones de eficiencia energética, al conseguir crear unas buenas condiciones microclimáticas y de confort térmico.

Los numerosos ejemplares de estas tipologías domésticas, que perviven en el centro histórico de Granada, con especial incidencia en el barrio declarado Patrimonio Mundial, el Albaicín, han hecho que los esfuerzos institucionales se dirijan a preservar sus valores patrimoniales y de identidad a través de la expresa protección de estas unidades en los planeamientos urbanísticos.

Los diferentes métodos de análisis y de intervención empleados por los profesionales de la arquitectura en los últimos treinta años en este campo, nos permiten generar un corpus práctico significativo sobre el que investigar. Analizar la evolución de esta unidad y de los criterios para su conservación a través de las prácticas rehabilitadoras, es el objetivo de este estudio. A partir de éste se han obtenido resultados y conclusiones extrapolables fuera del ámbito del Albaicín, pudiendo ser tales estrategias válidas para las políticas de intervención en otros ámbitos de arquitecturas populares.

\section{DESCRIPCIÓN DEL PATIO MUDÉJAR GRANADINO}

El patio mudéjar presenta elementos estilísticos, formales y constructivos de gran interés y singularidad (1) (2).

Su planta tipo es rectangular, aunque su diseño se hace dependiente de la forma del solar donde se integra, lo que hace que existan variantes cuadrangulares e incluso triangulares -San Juan de los Reyes 94-. En su constitución se mantuvieron las técnicas constructivas, decorativas y características tipológicas de la casa nazarí (3), manifestándose la influencia castellana, en la disposición de un mayor número de galerías que facilitaban la comunicación a las salas en los pisos superiores y en la decoración tallada de zapatas y canecillos de madera (4).

La morfología en planta baja se constituye mediante pórticos que rodean al patio (5) dispuestos sobre ménsulas, pilares o pilastras de mampostería o ladrillo de distinta sección circular, cuadrada o achaflanada en las aristas-, que alternan con columnas de arrastre nazaríes de mármol blanco o de nueva talla de piedra de Sierra Elvira de orden corintio simplificado o toscano (1). En el nivel superior, se sitúan las estrechas galerías, cuyo número depende del de pórticos, del de crujías, de la forma del patio, de la situación de la escalera y de la orientación, estableciéndose un número entre uno y cuatro, aunque el de crujías varía entre dos y cuatro (6). Los soportes de madera de este nivel, los denominados pies derechos, eran de sección cuadrada o rectangular hasta la altura del barandal, cambiando su sección desde esa cota a circular, ovalada u ochavada hasta casi la altura de la zapata; la parte final del fuste era cuadrada o rectangular con adorno de mocárabes o molduras de tipo gótico. Se adoptaron las zapatas castellanas realizadas con distintas tallas que iban desde las lobuladas y de tracería gótica hasta las antropomorfas y zoomorfas, siendo de mayor tamaño las de planta baja. De madera también las barandas y balaustres de las galerías que seguían modelos góticos o renacentistas (7). La importancia de los pisos altos se destacaba con mayor profusión ornamental en las galerías.

$\mathrm{Al}$ interior, el patio estaba pavimentado y dotado de alberca central. En torno a éste, se repartían las estancias especializadas funcionalmente. Los accesos de las principales estaban enmarcados por arco angrelado o ménsulas de yeso en las esquinas superiores del vano adintelado.

En las techumbres se emplearon alfarjes en pórticos y galerías, constituidos por alfarjías, cintas y tablazón, sistema constructivo que venía a ser una simplificación del nazarí al resolver los techos mediante jácenas de madera, apoyadas en pilastras o en soportes centrales, vigas embrochaladas en otras por uno o los dos extremos, y en voladizo mediante dobles canes empotrados en los muros (4). Cuando tenían que cubrir luces mayores eran de doble orden. Las soluciones más modestas prescindían de las cintas. Volados hacia el patio, se situaban los canecillos de madera, la mayor parte reutilizados.

Un último apartado lo constituyen los revestimientos y las técnicas decorativas. Entre las más habituales, la pavimentación resuelta con ladrillos mazaríes, baldosas cerámicas, incluso ladrillo vidriado. La cal revestía los muros de carga, mientras las yeserías formalizaban los arcos de acceso a las salas principales y las tacas en jambas, empleándose alicatados en zócalos, jambas y almatrayas. La pintura mural se reservaba para las albanegas de los arcos y los frentes del patio. Algunos alfarjes recibían decoración pictórica con motivos vegetales y geométricos. En cuanto a la carpintería, son notorios los ejemplares de puertas de las salas incluyendo las gorroneras de madera y las quicialeras de piedra. Las de tradición nazarí, estaban compuestas por tableros con decoración ataurejada, clavos en el anverso y peinazos en el reverso. Las de tradición castellana, constituidas por peinazos y cuarterones tallados a una o dos caras con acanalados verticales. Las ventanas se conformaban por hojas de cuarterones lisos dotados de postigos.

\section{METODOLOGÍA DE ESTUDIO Y MUESTREO}

El cuerpo de este estudio, desarrollado en el marco de la tesis doctoral de Dña. M. ${ }^{\text {a }}$ Lourdes Gutiérrez Carrillo titulada Mudéjar granadino: valores patrimoniales y conservación, analiza más de 400 intervenciones de conservación y rehabilitación durante los últimos treinta años dirigidas a este singular patrimonio, con especial incidencia en el barrio del Albaicín. De ellas, prácticamente 2/3 han tenido como protagonista la arquitectura doméstica, dándose casos de actualización del uso original así como transformaciones principalmente a uso hotelero, institucional y/o docente.

De tan extensa muestra se han analizado los problemas de conservación de esta tipología, y en particular de la unidad del patio, ya que buena parte de las proyectivas han supeditado la recuperación de la arquitectura doméstica a la reconstitución del patio. 


\section{DESARROLLO DEL ESTUDIO}

\subsection{Estados de conservación previos a la intervención}

Desvirtuación tipológica y funcional: las agregaciones parcelarias históricas y las reformas urbanísticas de finales del siglo xIx y principios del xx, hicieron que la arquitectura residencial del barrio del Albaicín, se viera fuertemente modificada en su realidad formal y constructiva al colectivizarse las arquitecturas residenciales unifamiliares. El esquema habitacional se orientó hacia la ocupación del espacio de patios y galerías, la supracompartimentación de las salas interiores, la creación de piezas de paso sin ventilación y la apertura y/o cierre anárquico de huecos a patios. Junto a ello fue común la construcción de entreplantas y añadidos con una incoherente mezcolanza de formas y estilos (Figura 1).

La nueva redistribución implicó la integración de volúmenes cubiertos por placas de fibrocemento o PVC. En ocasiones, los huecos centrales fueron forjados superiormente, además de ocupar las galerías, cegándolas con fábrica de ladrillo con el fin de aumentar la superficie útil de las viviendas.

La necesidad de independencia de las nuevas viviendas, originó la creación de numerosos cuerpos de escalera que facilitaron la comunicación directa de cada una de ellas con el patio generando complejas disposiciones con invasiones parciales de la superficie -Santa Isabel la Real 19-, dando lugar a una ilógica y laberíntica articulación de los itinerarios internos.

La ausencia original de baños y retretes hizo que desde principios del siglo xx éstos se situaran en las áreas de distribución común para uso comunitario -Santiago 5 o Pardo 5-. La disposición de bajantes en los ángulos del patio, las incorrectas conexiones y la falta de mantenimiento, hicieron de las esquinas los puntos más afectados por lesiones derivadas de la humedad.
Alteraciones técnico-constructivas: ha sido notoria la degradación general causada por la ausencia de mantenimiento y conservación o por el desarrollo de soluciones incorrectas.

Las estructuras murarías han delatado falta de respuesta ante nuevas solicitaciones manifestando grietas y fisuras. Las filtraciones de aguas negras y la ejecución de revestidos con morteros de cemento han favorecido los efectos de la humedad por capilaridad en las partes bajas de los muros y en pavimentos.

Las de mayor gravedad afectaban a las galerías con desplomes, desplazamientos y flechas estructurales que han conllevado la pérdida de resistencia siendo necesario apuntalamientos provisionales -Babolé 3, Cristo de las Azucenas 2- (Figura 2). Entre las más numerosas, las roturas de vigas por el exceso de carga y débil escuadría de las piezas; vencimiento de los apoyos por la presencia de esfuerzos a cortante; y rotura o desprendimiento de entrevigados y cielos rasos. Son destacables las pudriciones de la viguería con alteraciones cromáticas y pérdidas de resistencia por filtraciones de agua desde las cubiertas, por la falta de ventilación en los empotramientos en el muro o por la rotura u obstrucción de canalizaciones.

De notable consideración las pérdidas de sección por ataque de xilófagos; las perforaciones y embutidos de canalizaciones en los elementos lignarios; desprendimientos, abultamientos, envejecimiento, desgaste y pérdidas de la capa pictórica.

\subsection{Objetivos generales de las intervenciones analizadas}

Al tratarse de edificios muy modificados, el objetivo principal de las intervenciones ha sido la devolución de la arquitectura doméstica a su estructura orgánica, centrada en la reconstitución tipológica, constructiva, formal y funcional del patio. $\mathrm{Su}$ recuperación permite el entendimiento de la construcción doméstica granadina, su funcionamiento interno y visibiliza la conexión con el entorno al que perteneció.
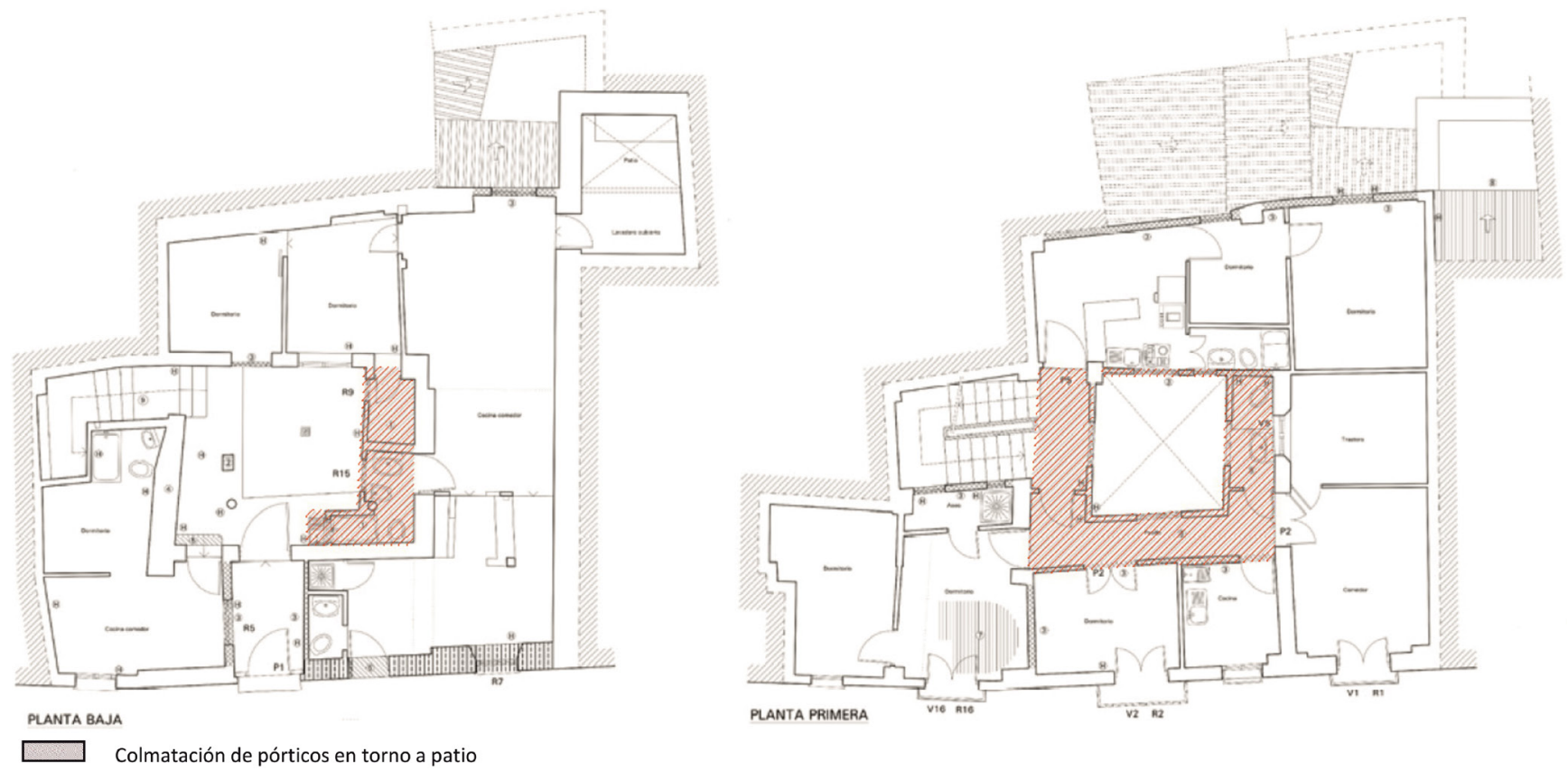

Figura 1. Estado previo vivienda Marañas 5. Archivo Francisco Maeso. 


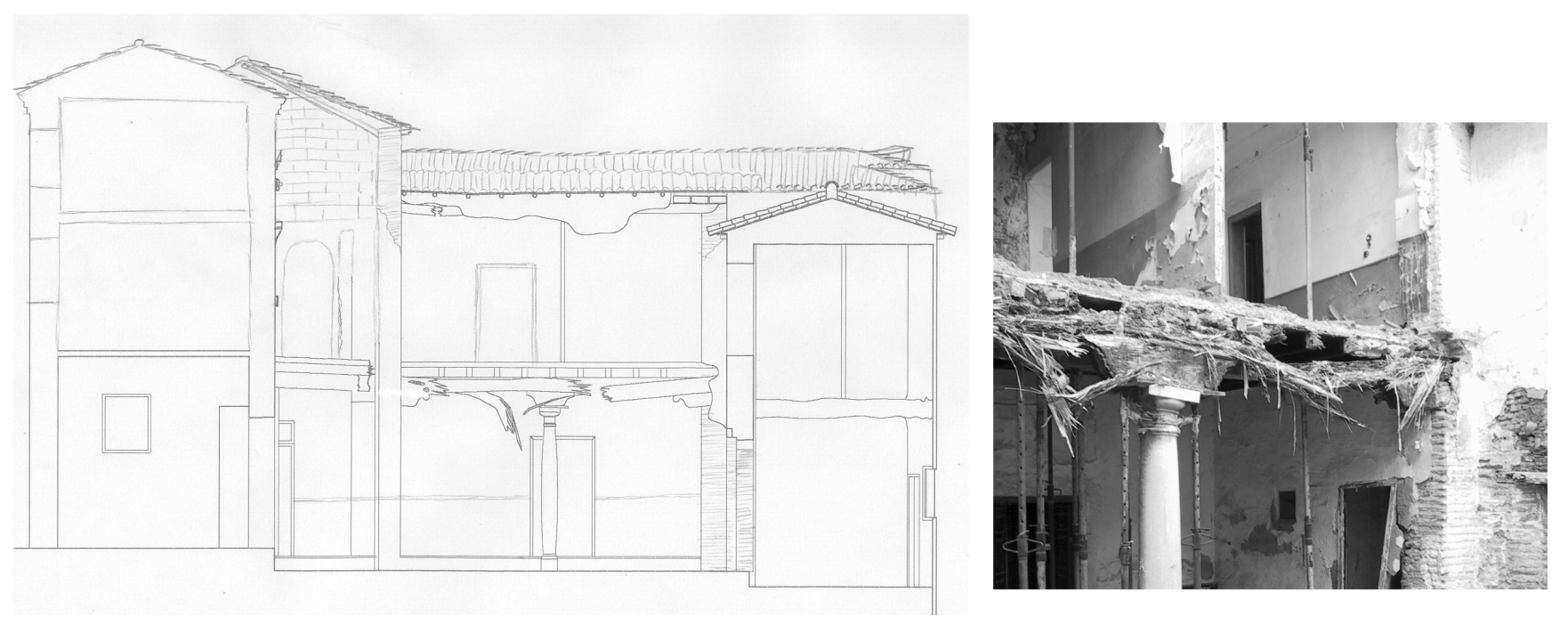

Figura 2. Daños estructurales en alfarje de pórtico en C/ Cristo de las Azucenas 2. Archivo Guillermo Sánchez.

Los objetivos secundarios consistieron en:

- Conocimiento actualizado de la morfología y de la transformación histórica de la unidad espacial del patio.

- Recuperación de sus valores arqueológicos, arquitectónicos y estéticos.

- Conservación crítica de las estructuras originales y de los testigos de intervenciones históricas de interés.

- Integración arquitectónica y funcional del patio en los nuevos usos adoptados en los inmuebles.

- Legibilidad, compatibilidad y reversibilidad de las intervenciones contemporáneas en relación a la puesta en valor de los materiales y las técnicas constructivas tradicionales.

- Recuperación de la funcionalidad del patio desde el recobro de los modelos históricos de eficiencia energética, poniendo en valor los principios de sostenibilidad.

\subsection{Análisis de los criterios de intervención}

Los objetivos planteados en el punto 4.2. se desarrollaron según distintos criterios de intervención. A grandes rasgos hemos sistematizado los siguientes:

Recuperación espacial del patio mudéjar mediante deconstrucciones e integraciones en estilo: para conseguir una adecuada relectura espacial del patio se tendió a realizar radicales limpiezas, eliminando lo incoherente y descontextualizado -apertura de cegados de pórticos, liberación de elementos de interés-. La devolución a un estadio inteligible ha estado basada en el respeto y atenta interpretación de lo existente y en la valoración de las aportaciones históricas, aunque en algunos casos las reinterpretaciones a partir de analogías formales han derivado en reconstrucciones excesivas.

Convivencia de técnicas tradicionales y contemporáneas en los refuerzos estructurales: ha sido determinante devolver el correcto comportamiento resistente a los elementos estructurales, muy afectados por la extrema exposición a la humedad y al aumento de cargas. Ha sido referente el empleo de materiales y técnicas constructivas tradicionales en la consolidación y mantenimiento de los elementos de interés. También en las reintegraciones y sustituciones, garantizando compatibilidad y comportamientos análogos a los preexistentes. Además, se ha apostado por la inserción de materiales y soluciones contemporáneas, que han tenido un papel colaborante en la función estructural.

Revalorización de elementos singulares: especial desvelo ha supuesto la recuperación de los elementos decorativos ya que cualifican en alto grado la arquitectura. Las vertientes de actuación se han vinculado a la conservación y restauración de los restos con reintegraciones por anastilosis, a la eliminación de objetos descontextualizados, y a la des-restauración de aportaciones anteriores lesivas para el conjunto histórico.

Recuperación funcional de los patios: se ha pretendido recobrar la función práctica, arquitectónica y social, recuperando la distribución hacia las dependencias habitacionales a través de la secuencia zaguán-patio-galería; favoreciendo los principios de eficiencia energética y sostenibilidad gracias a la consecución de iluminación y ventilación natural directa a las estancias dispuestas en torno a él; y revalorizando el patio como punto de reunión y encuentro.

\subsection{Estudios previos detectados en los casos analizados}

Los estudios históricos y documentales aunque preceptivos desde la metodología doctrinal, han tenido distinta profundidad según si su contratación fue pública o privada. Ellos han aportado datos sobre el inmueble, la sociedad que lo erigió y los usuarios del mismo, desvelando alteraciones, adiciones, soluciones técnico-constructivas y espaciales. Asimismo ha sido objetivo el inventario de las piezas y elementos de valor.

En la mayoría de casos se han realizado estudios arqueológicos asociados al Programa de Arqueología de la ciudad de Granada, incluyendo en los últimos años análisis estratigráficos de estructuras emergentes. Éstos han desentrañado la configuración y traza de los paños, los materiales y técnicas constructivas o los elementos ornamentales. Entre los testigos más buscados, la secuencia y dimensión de huecos en los frentes de patio, desvelando umbrales, tacas, ventanitas de coronación, cajeados de gorroneras y/o quicialeras, lo que ha permitido elaborar la imagen de la composición en base a unos restos concretos y fiables. Sin duda la investigación arqueológica realizada en las casas San Buenaventura 2 ha alcanzado las más altas cotas de rigor metodológico. 
También han sido destacables estudios basados en metodologías analíticas que han determinado la caracterización del material, su envejecimiento, así como las causas de alteración y las características de compatibilidad para aquellos a incorporar en el proceso de intervención. Estos análisis no han sido generalizados, teniendo especial incidencia en San Buenaventura 2 y Gloria 5, entre otros.

\subsection{Análisis de actuaciones realizadas}

Se ha estructurado el análisis de las soluciones propuestas en las diferentes intervenciones en base a los elementos constructivos y condicionantes funcionales que configuran el patio.

\section{Pórticos}

Estos espacios cegados y ocupados, se liberaron definiendo las zonas comunes y devolviéndoles su correcta organización espacial. Se eliminaron las humedades y se consolidaron y repararon los elementos estructurales y decorativos.

Pilares y pilastras: el principal objetivo fue la recuperación de la funcionalidad estructural mediante consolidaciones, reintegraciones y completamientos matéricos. Los criterios adoptados han sido distintos en relación a su carácter estético, resultando sus variantes principales:

a) Visibilizar la factura formal y constructiva descubriendo la fábrica de ladrillo o piedra -Cuesta de San Gregorio 13, Horno de Hoyo 4, Minas 11 o Zafra 10-. En Cristo de las Azucenas 2 se optó, tras el saneo de piezas y juntas de mortero, por completar las faltas con material de nueva factura pero de similares dimensiones, estableciéndose la distinción en la coloración más rojiza de las piezas aportadas. Seguidamente el pilar fue homogeneizado estéticamente con rejuntado de mortero de cal.

b) Mantener las soluciones revestidas con morteros de cal y mixtos -pórtico meridional de Cuesta de las Tomasas 120 la vivienda de Hernán López el Feri-.

c) Incorporar estos elementos según modelos análogos a los de otros inmuebles, armonizándolos con el resto de la composición -Horno de San Agustín 5-. Esta práctica ha convivido con la ejecución de recrecidos en sección que favorecen el aumento de la superficie de apoyo de las carreras y por tanto la misión estructural -Pardo 5-.

Columnas: la tendencia más habitual ha sido realizar tareas de limpieza y restauración. En Horno de la Merced 2 se limpiaron restos de pintura, se repararon daños superficiales y hubo reintegraciones con material similar, finalizando con un pulido general de la superficie. Han existido reposicionamientos en su correcto lugar con el fin de recuperar una función estructural y tipológica -Santa Isabel la Real 19-. Asimismo las modificaciones de rasantes en el tiempo, han enterrado sus basas, perdiéndose la visión integral del soporte. De ahí que en Zafra 8 se realizara un cajeado bajo rasante dejando vista la basa. Las faltas por expolio o por daños fatales durante el desmontado, han justificado restituciones totales o parciales en el mismo material, tomando como referencias formales los desparecidos -Elvira 78, no de la Merced 2-, o mediante recomposición en estilo o por analogía sin acogerse al valor histórico. También han existido reintegraciones parciales con morteros y forrados en piedra de Sierra Elvira cuando los pedestales eran de ladrillo para dar uniformidad visual al elemento.

\section{Pavimentos}

El solado constituye un recurso bastante eficiente para significar estadios anteriores y datar propuestas contemporáneas. Las fórmulas más secundadas han sido:

a) Modificar o mantener los niveles heredados entre el área central y la porticada. En Placeta Albaida 4 se apostó por el mantenimiento del cambio de rasante, llegándose en Cuesta de las Tomasas 12 a sobreelevar el pórtico con una pequeña tabica. Benalúa 11 y Cuesta de la Victoria 9 ejemplifican la continuidad de la rasante, al ascender la cota por inclusión de la instalación de suelo radiante; igualmente en San Juan de los Reyes 84, al integrar viviendas sociales, se igualan los niveles para favorecer la accesibilidad. En estos casos, el despiece y disposición del pavimento contribuyen a la diferenciación espacial. En ocasiones se han incluido fajeados cerámicos en torno al espacio central dividiendo las dos superficies -Cuesta de la Victoria 9- o dibujos de diseño de lazo y olambrillas (Figura 3).

b) Restituir con reintegraciones matéricas los primitivos pavimentos tras desvelarlos arqueológicamente. En el área central del patio de Elvira 78 se recuperó el empedrado de guijos completando las lagunas con material similar pero de distinto diámetro, favoreciendo la distinción entre el original y el aportado. En Yanguas 11 y San Martín 16, los restos del empedrado fueron reparados con guijarros sobre capa de mortero y fraguado con mortero bastardo de cal y cemento blanco.

c) Mantener el solado existente, incluso en soluciones como la de Carrera del Darro 23, donde la creación de un sótano bajo el espacio de patio quedaba sujeto a la restitución de la solería original de piedra.

d) Disponer nuevos solados en analogía material y compositiva a las tipologías de referencia. La pavimentación ha sido clave en la composición y en la salvaguarda de valores patrimoniales. Ha contribuido a la diferenciación espacial entre el área porticada y el área descubierta a través del material.

Las calidades seleccionadas han sido el barro -gres, barro antiguo y barro prensado-, en baldosas o ladrillos a sardinel o espiga, para todos los espacios; y la piedra de Sierra Elvira, con acabados lisos, apomazados o abujardados principalmente en la planta baja. Éstos han podido ocupar toda la superficie o se han combinado en el área central con soluciones de diseños de guijos -Cuesta de las Arremangadas 6- (8) (Figura 3).

Junto a lo anterior, la funcionalidad ha sido mejorada gracias al restablecimiento de pendientes y de puntos de evacuación con canales perimetrales a la alberca o sumideros más o menos centrados.

\section{Albercas}

Son importantes por la caracterización que adquieren en la definición del patio, habiendo sido prioritaria su búsqueda durante la fase de estudios previos. Las proyectivas incluso, a pesar de la escasez de datos de su existencia o pervivencia, promueven su integración reproduciendo desde la analogía modelos del entorno -Ceniceros 28-.

La pervivencia de los restos ha sido muy desigual, pero en buena parte han permitido el trazado formal y dimensional 


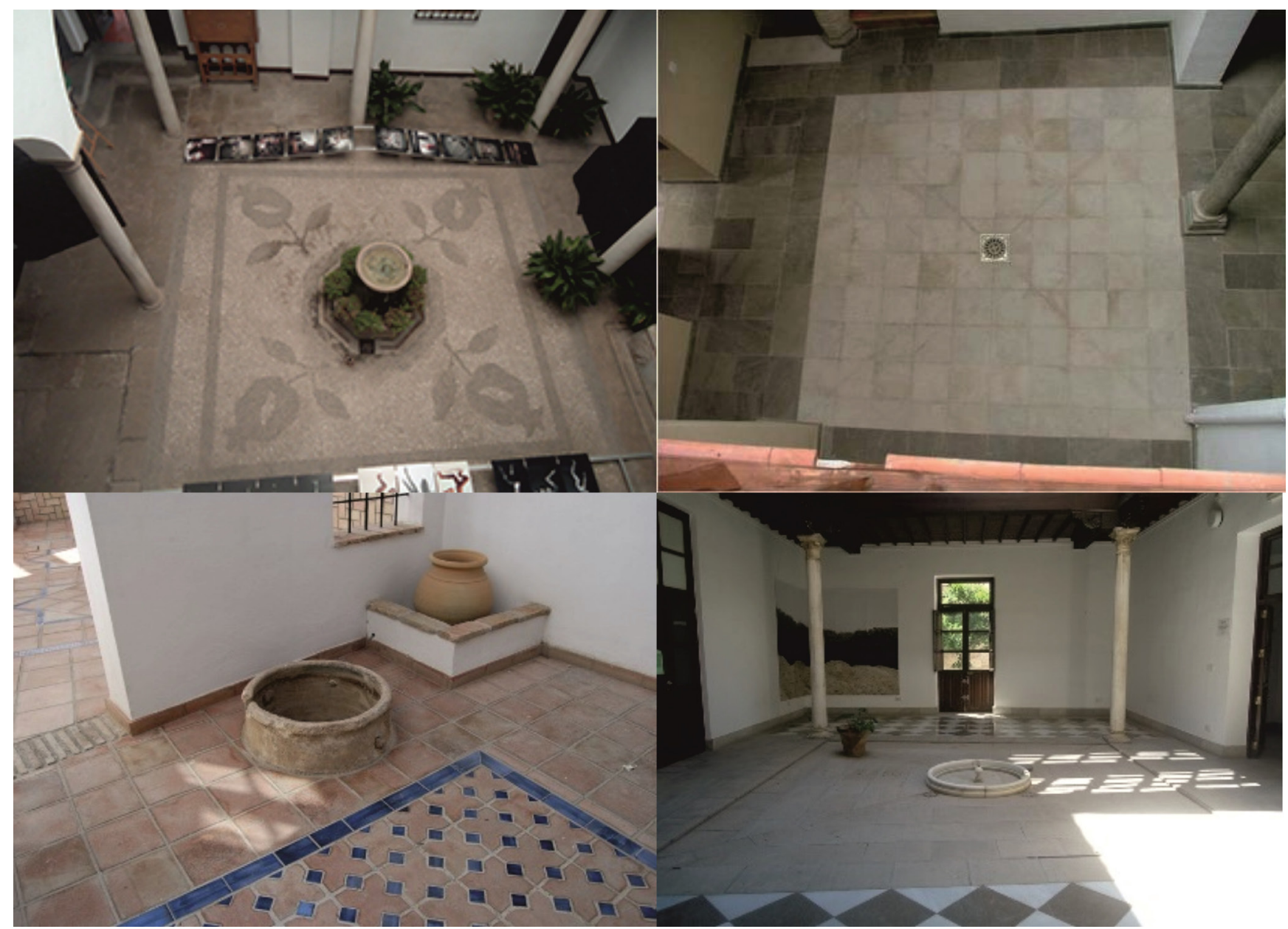

Figura 3. Distintas soluciones de solados en patios. Archivo Lourdes Gutiérrez.

de las albercas. Las principales tendencias han sido la puesta en valor de los restos y su reinterpretación; o bien su protección y cubrición, previa documentación, sin reinterpretarlos en un nivel superior.

En Cuesta de la Victoria 9 aparecieron varios estratos correspondientes a distintas morfologías de alberca que confirmaban la secuencia de varios momentos constructivos. El proyecto recuperó la correspondiente a la vivienda mudéjar. Se desechó el estado contemporáneo y se protegieron con geotextil los restos del periodo nazarí (9).

La intervención arqueológica realizada en el patio de Cuesta de San Gregorio 13 constató restos de infraestructuras hidráulicas y de una alberca asociada al periodo nazarí. La solución adoptada fue ocultarla, previa protección con film impermeable, pavimentando sobre ella con baldosas de piedra de Sierra Elvira y modificando el sistema de recogida de pluviales para que no afectara a dichos restos.

\section{Galerías}

Las operaciones han buscado recuperar los aspectos formales, tipológicos y constructivos al desvelarlas, completarlas y a veces rehacerlas en base a la tecnología y diseños primitivos o por analogía. Las principales orientaciones han sido:

a) Recuperar estructuras singulares, descubriendo los elementos lignarios, pies derechos, balaustradas y alfarjes, procediendo a su conservación mediante limpiezas mecánicas, desinsectación, desinfección y consolidación, con especial atención a las policromías de algunos ejemplares.

Al demoler los cierres de fábrica que contenían estos elementos, ha sido frecuente comprobar la pérdida de piezas originales debiendo adoptar medidas de reposición que mostraran con suficiente legibilidad las reintegraciones o completamientos de fragmentos desaparecidos -Carnero 4-. También se han integrado piezas de este tipo Yanguas 11-, donde ante la ausencia de pies derechos el proyecto los reproduce a partir de uno original.

b) Reconstruir espacialmente las galerías perdidas. Cuando la galería ha desaparecido, ha primado la recuperación de los volúmenes necesarios para redefinir la tipología y su función distributiva.

Las reconstrucciones de los años 80 primaron el uso de tecnología contemporánea, al ejecutarse un núcleo funcional-estructural de obra nueva y una corteza exterior que guardase relación armónica con los cánones formales de la tipología. Las intervenciones más actuales han valorado además la autenticidad material. En Horno de San Agustín 5 , el muro oeste medianero de fábrica de dos alturas presentaba restos de un frente originario de época nazarí muy transformado. Entre los elementos identificados: el acceso a la sala baja en el centro de la composición con sus tacas laterales, restos de arcos angrelados de yeso, otros tipos de huecos e hileras de mechinales. En éstas últimas se reubicó la nueva viguería que conformaría la galería del 
patio en ese frente, haciendo una recomposición y puesta en valor de los restos, que contribuyó a la definición del alzado (Figura 4).

c) Mantener cierres de fábrica. Cuando éstos han estado consolidados y ante la falta de testigos documentales o materiales de un estadio anterior, las actuaciones se han encaminado hacia su permanencia contribuyendo al incremento de superficie útil de las salas -Elvira 78-.

d) Adecuación técnico-constructiva. Realizando principalmente consolidaciones y refuerzos estructurales donde la inserción de materiales distintos a la madera -hormigón armado y acero laminado- responden a requerimientos constructivo-funcionales que a veces han pro- vocado cambios en el comportamiento original de la estructura.

Las modificaciones de los planos de cubierta ocasionaron desplomes y vuelcos en las galerías por falta de atado, obligando a su corrección mediante atirantados a tracción, cambios en la disposición de viguerías, o incluso sustituciones de éstas. El cuerpo de cubiertas que cubre el frente Norte del patio de Cuesta de San Gregorio 13 sufrió una inadecuada actuación en la década de los años 90 consistente en la transformación de la tradicional solución asillada ${ }^{1}$ por una de par e hilera sin quiebro en el faldón. Este cambio formal provocó el empuje y desplazamiento
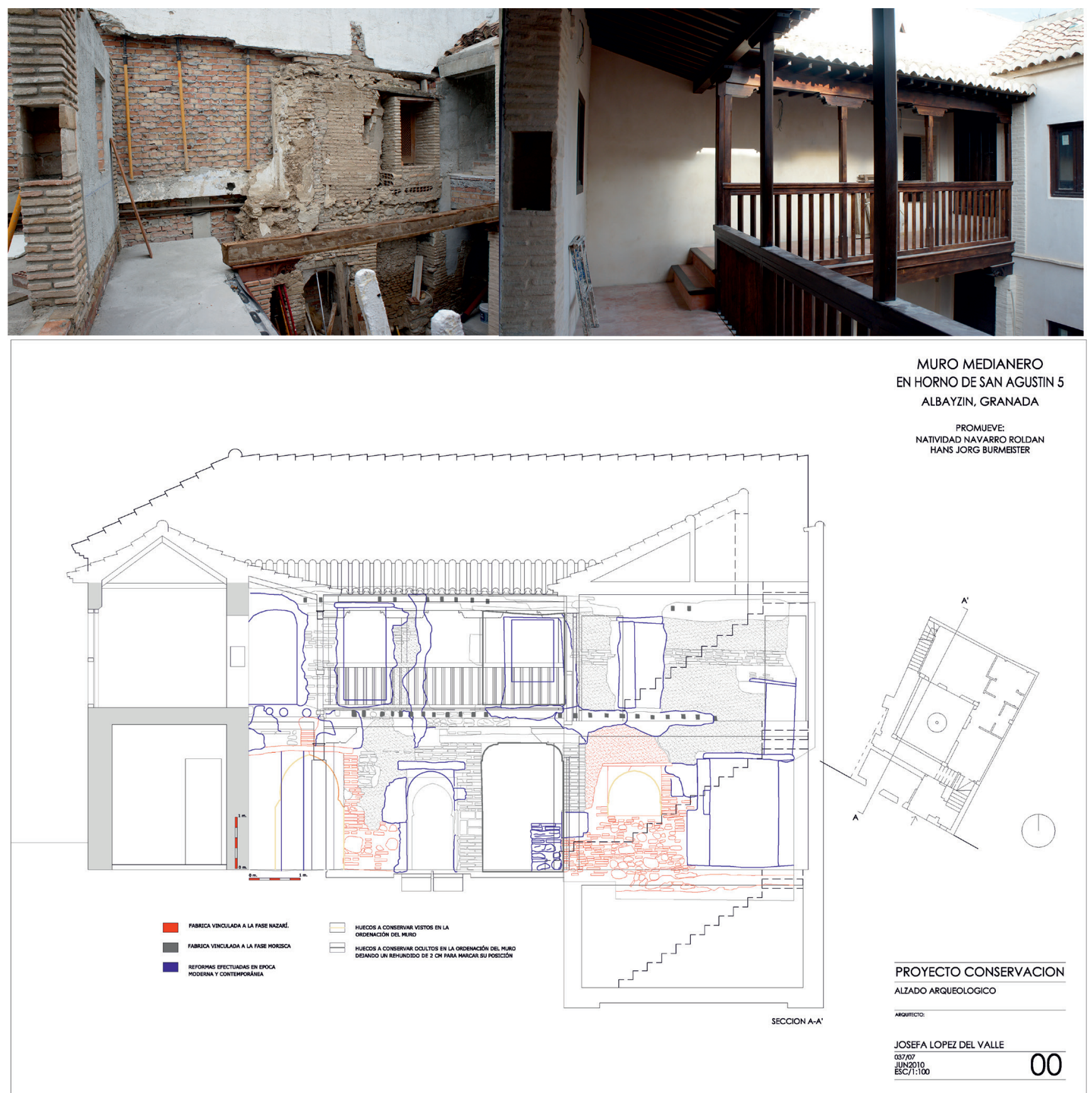

Figura 4. Estado previo del paño oeste de Horno de San Agustín 5. Galería integrada según las alturas que marcaban los empotramientos de los mechinales. Plano de secuencia estratigráfica de restos del muro. Archivo Josefa López.

${ }^{1}$ Se trata de aquel tipo de cubierta en la que el alero suaviza la pendiente en relación al resto del faldón. 
de la galería, con su consecuente desplome. Su recuperación atendió al desmontado de la cubierta y su restauración según el modelo asillado original, y al apuntalamiento y atado de la galería con un tirante metálico para que no avanzara el desplome que sufría.

e) Reparar pies derechos y balaustradas. El extremo inferior de los pies derechos, de madera de pino rojo en origen, ha manifestado daños debido a la exposición a la humedad. Su recuperación se ha basado en la disposición de prótesis inferiores -San Martín 16- (10), resultando las más interesantes los ensamblajes con cajeado cuadrangular para evitar el giro.

La recomposición de pies derechos de madera ha buscado fidelidad a la proporción y a la esbeltez original desechando perfiles heredados de mayor escuadría que le conferiría un carácter tosco a la composición. En algunos casos, al carecer de datos sobre la situación original de estos soportes, se ha optado por el uso de perfiles de acero para reproducir su morfología y función -Placeta Almirante 1-. La situación de la balaustrada respecto a los pies derechos ha sido profusamente analizada por Antonio Orihuela (10). Incorporamos a este estudio las soluciones contemporáneas que se alejan de la tradición, como la de Minas 8 donde la barandilla se configura a modo de bastidores independientes que no entestan con los pies derechos en el barandal. Unas lañas conectan dicho bastidor con los soportes verticales a una cota inferior, produciéndose allí erróneamente también el cambio de sección del pie derecho. En Cuesta de Aceituneros 6 se ha sustituido el tercio inferior del balaustre por un pequeño murete, descendiendo el pie derecho hasta su apoyo original. En Placeta del Almirante 1 la balaustrada del primer nivel del patio se resuelve con un ligero paño de vidrio ante la falta de testigos originales que degenera en un simplismo excesivo.

f) Refuerzos estructurales. El principal problema de los alfarjes ha sido la pérdida de capacidad mecánica, obligando a efectuar intervenciones estructurales de consolidación con sustituciones parciales o totales - carreras, alfarjías y tablazón-, reintegraciones, adecuación de escuadrías y/o prótesis puntuales mediante ensambles. En Placeta de los Castilla 6, la excesiva degradación de la carrera afectada por flecha, justificó su sustitución por otra de la misma sección que admitiera un correcto encaje en el conjunto.

El vuelo de la galería sobre el pórtico con el fin de aumentar su anchura, ha sido la causante de notables daños en las cabezas de las vigas del alfarje inferior. La mayor exposición a la humedad de éstas ha provocado su pudrición con la consecuente pérdida de resistencia en el extremo. Otros inconvenientes que se generan son la apertura de nuevos cajeados, nuevos apoyos o la ampliación de los existentes(10). En San Martín 16 este problema se resolvió recortando las cabezas de vigas podridas y doblando la carrera hacia el interior con otra pieza suplementaria, sobre la que apoyaron las alfarjías recortadas. Esta solución obligó al retranqueo de la galería, provocando la pérdida de anchura.

En los refuerzos, los métodos basados en la incorporación de capas colaborantes de hormigón armado ha permitido devolver estas estructuras a una funcionalidad óptima manteniendo la materia heredada sin detrimento estético. El reparto uniforme de cargas ha posibilitado a las piezas más débiles o dañadas, quedar inmersas en la estructura, siendo su trabajo absorbido por las contiguas. El acero ha permitido resolver de un modo puntual la pérdida de capacidad portante contribuyendo a la conservación de elementos leñosos. En el alfarje del pórtico de Placeta del Almi- rante 1 , el refuerzo fue realizado mediante una estructura metálica de la que quedaría colgada la antigua carrera. El conjunto formado por carrera-vigas-perfil metálico quedó oculto tras unos tableros que aportaban sensación de rigidez a la composición por la altura del canto conseguido.

\section{Estructuras murarias}

Las acciones se han centrado en mejorar su capacidad resistente mediante reintegraciones de ladrillo cerámico antiguo, obtenido de la demolición de la propia construcción o proveniente de derribos y/o de tejar, con texturas y coloraciones más similares a las históricas. Otras acciones se han dirigido a eliminar los problemas ocasionados por el ascenso de humedad por capilaridad -electroosmosis, barreras impermeables y/o tubos porosos-, con resultados de distinta efectividad.

Estos lienzos también han visibilizado las consecuencias de los cambios de uso sufridos en la arquitectura doméstica desde el primitivo carácter unifamiliar al posterior plurifamiliar. Las intervenciones se han desarrollado en función del grado de conservación, alineándose en:

\section{Vanos}

a) La reordenación de huecos mediante diversas soluciones. En estructuras consolidadas y en nuevos usos, la tendencia ha sido mantener los huecos heredados y transformados a lo largo del tiempo, regularizando sus formatos -Callejuela de San Bartolomé 4-.

Para nuevas necesidades de habitabilidad se ha optado por abrir huecos -Marañas 5, Zafra 8-, o se ha ampliado la dimensión de los existentes, significando la intervención contemporánea -Santísimo de San Pedro 4-. Otras fórmulas han tendido a su cegado al no tratarse de aperturas de origen, realizadas sin criterio -Cuesta de las Arremangadas 6-.

b) La vuelta al diseño original de paramentos. En esta tendencia se enmarca la devolución de las alacenas al interior de las salas, cegando anteriores aperturas -Cuesta de la Victoria 9- (10) (Figura 5); aunque hemos de señalar que con cierta frecuencia se ha mantenido la transformación de anteriores alacenas en ventanas por necesidades de iluminación y ventilación -San Luis Alto, 9, placeta de los Castilla 6-.

\section{Revestimientos}

Se han detectado tres acciones mayoritarias:

a) La eliminación de revestimientos para favorecer el entendimiento constructivo. Ante tal desprotección del frente murario, se ha dedicado especial atención al tratamiento de las juntas. Han sido limpiadas, cepillando el material descohesionado, y rellagueadas con dosificaciones de calarena o cal-cemento-arena que han mejorado la plasticidad y resistencia de la masa. La elección del tipo de junta -espesor y morfología - condiciona la solidez y rigidez de la fábrica y consigue la armonía estética del lienzo. Las principales ejecutadas: enrasadas, retranqueadas o matadas superiormente.

b) La nueva ejecución de revestimientos. Los beneficios que aporta el empleo de la cal han favorecido el uso de morteros de cal teñidos en masa, con una pequeña proporción de cemento o formulados con resinas. Han sido aplicados 


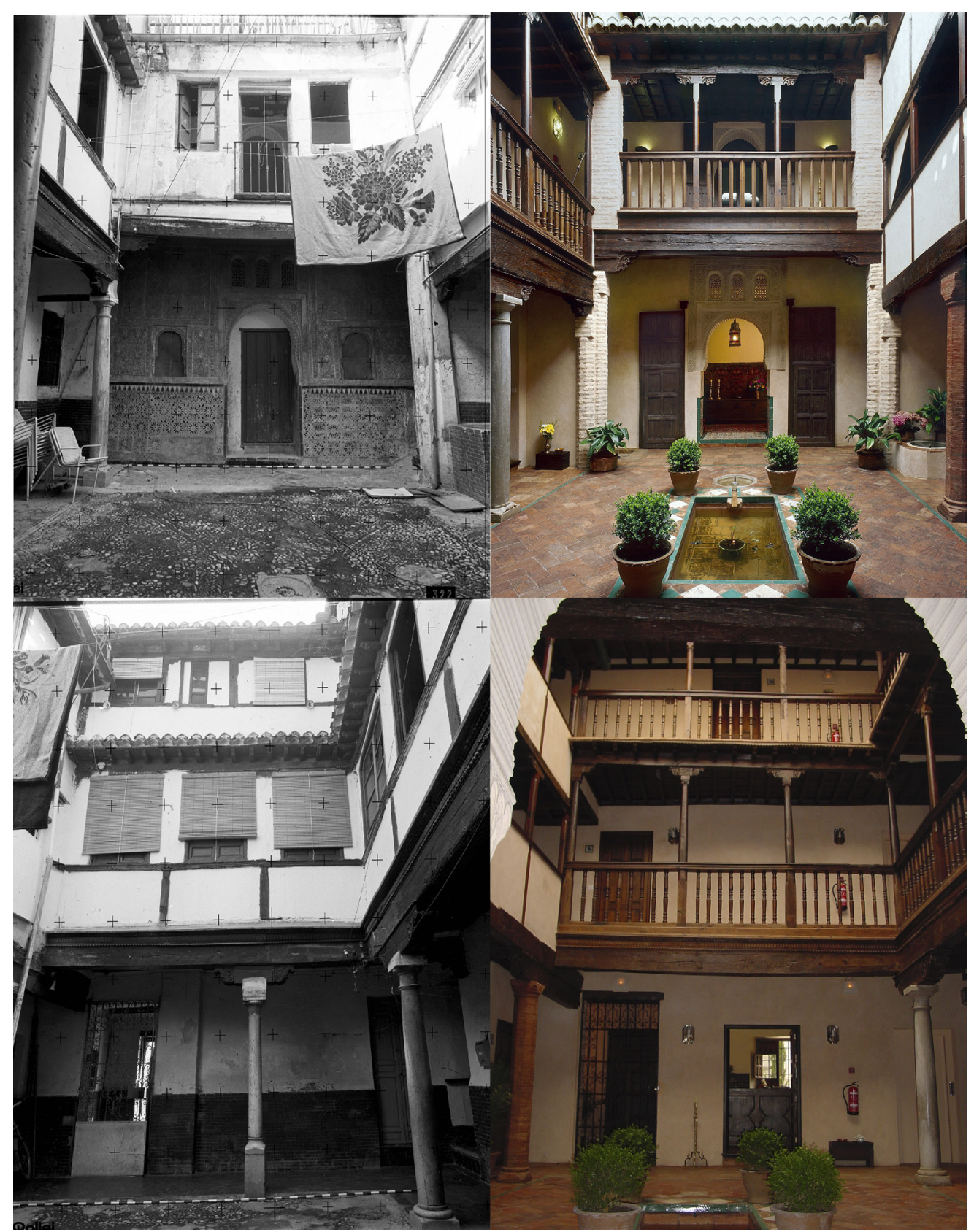

Figura 5. Alzados oeste y este del patio de Cuesta de la Victoria 9 antes y después de la intervención. Archivo Carlos Sánchez.

con llana otorgando texturas lisas o más finas aún cuando se han aplicado en varias capas con plana.

c) Como solución intermedia en fábricas vistas que buscan resultados más planos y mayor difuminado en el efecto estético, se han aplicado morteros mixtos de cal y cemento blanco sobre la junta enrasada «manchando» ligeramente la hilada de ladrillo.

\section{Aspectos decorativos}

Los problemas habituales detectados han sido la mutilación, el recorte formal y el estado de degradación, lo que ha contribuido a la decadencia de su imagen y a la puesta en riesgo de los soportes que los acogen, justificando incluso ejercicios de des-restauración. Estos trabajos tuvieron protagonismo en el tratamiento del paño occidental de planta baja de Cuesta de la Victoria 9 cuando se propuso la eliminación de la yesería historicista decimonónica y de los zócalos de alicatado (10).
Hay que añadir la desaparición de decoraciones por falta de criterio valorativo de su calidad, o por robo y expolio lo que ha provocado arrancamientos de su contexto original, principalmente de zapatas, pies derechos y otros elementos lignarios.

Su recuperación ha sido muy desigual primando:

a) Recuperación o reproducción de elementos de madera. Los recortes o faltas han dado origen a reintegraciones principalmente de zapatas, canecillos, balaustres y alfarjías. Entre los modos efectuados, el que ha considerado la reutilización de material de recuperación de la propia construcción buscando una imagen fidedigna al trazado original. Otros han atendido la restitución de la unidad figurativa con incorporaciones de diseño mimético, lográndose la distinguibilidad del aporte por la leve diferenciación formal, cromática o material. En Cuesta de Santa 
Inés 6, las zapatas del ángulo noreste, aunque presentan la misma talla que el resto, se diferencian por la madera empleada. Similar criterio tuvo la reintegración de las zapatas y canecillos del alero de Alberzana 1.

Otra opción ha sido la reinterpretación funcional con piezas esquemáticas. Así, en la hilada de canecillos que separaban los dos niveles en Pardo 5 o en las zapatas del segundo nivel de Marañas 3 se reintegró con ejemplares de diseño simplificado; en Carnero 4 los balaustres torneados que faltaban se reintegraron con otros de sección cuadrangular. Los alfarjes de pórticos y galerías también asumen esta diferenciación al emplear maderas similares, con idéntica escuadría en los elementos a sustituir pero sin decoración agramilada o pictórica (Figura 6).

b) Reintegración de yeserías mediante anastilosis o completamientos en estilo: los arcos angrelados que decoran los accesos principales, alacenas y tacas se han mantenido en desigual estado de conservación. Entre otros procedimientos, su recuperación formal se ha establecido mediante anastilosis. En Pardo 5 afloraron restos de yeserías que fueron reintegrados en el arco del extremo meridional del pórtico; y en Zafra 10, bajo el peldañeado de la escalera principal del inmueble se conservaban trozos del arco de yeso que delimitaba el ingreso a la sala de planta alta de la crujía oeste. Tras su identificación y limpieza fueron dispuestos en su posición original, reintegrando las partes perdidas. La imagen final adolece de mayor distinción entre el material original y el aportado. c) Reproducción de paños de mayor superficie a partir de testigos: gracias a la técnica arqueológica en el umbral del vano de acceso a la sala de planta baja de la crujía oeste de Cuesta de la Victoria 9, fue descubierta una almatraya morisca en mal estado de conservación. Durante su desmontaje, fueron desvelados restos de una anterior, que por su interés es la que se recuperó, integrando los restos originales en la reproducida.

\section{Modificaciones en las condiciones medioambientales y de eficiencia energética}

Las medidas adoptadas permiten reducir las necesidades energéticas del edificio, mejorando las condiciones de confort térmico del patio. Éstas, se han centrado en:

a) Cierres de galerías. La necesidad de conseguir mayor superficie útil en estos edificios rehabilitados ha motivado el uso de cerramientos acristalados que respetan la imagen recuperada, consiguen el objetivo de acrecentamiento de superficie útil y mejoran considerablemente las condiciones de confortabilidad térmica de todo el conjunto -Marañas 3, Horno de Hoyo 4, Guinea 19, Horno de la Merced 2-.

En casos como Cuesta de Santa Inés 6 o Callejón de la Botica 4 el cerramiento constituido por marco de madera con vidrio doble climalit de hojas correderas dispuesto tras la balaustrada, ha permitido usos polivalentes de estos espacios. En Zafra 10 y San Juan de los Reyes 94 las galerías

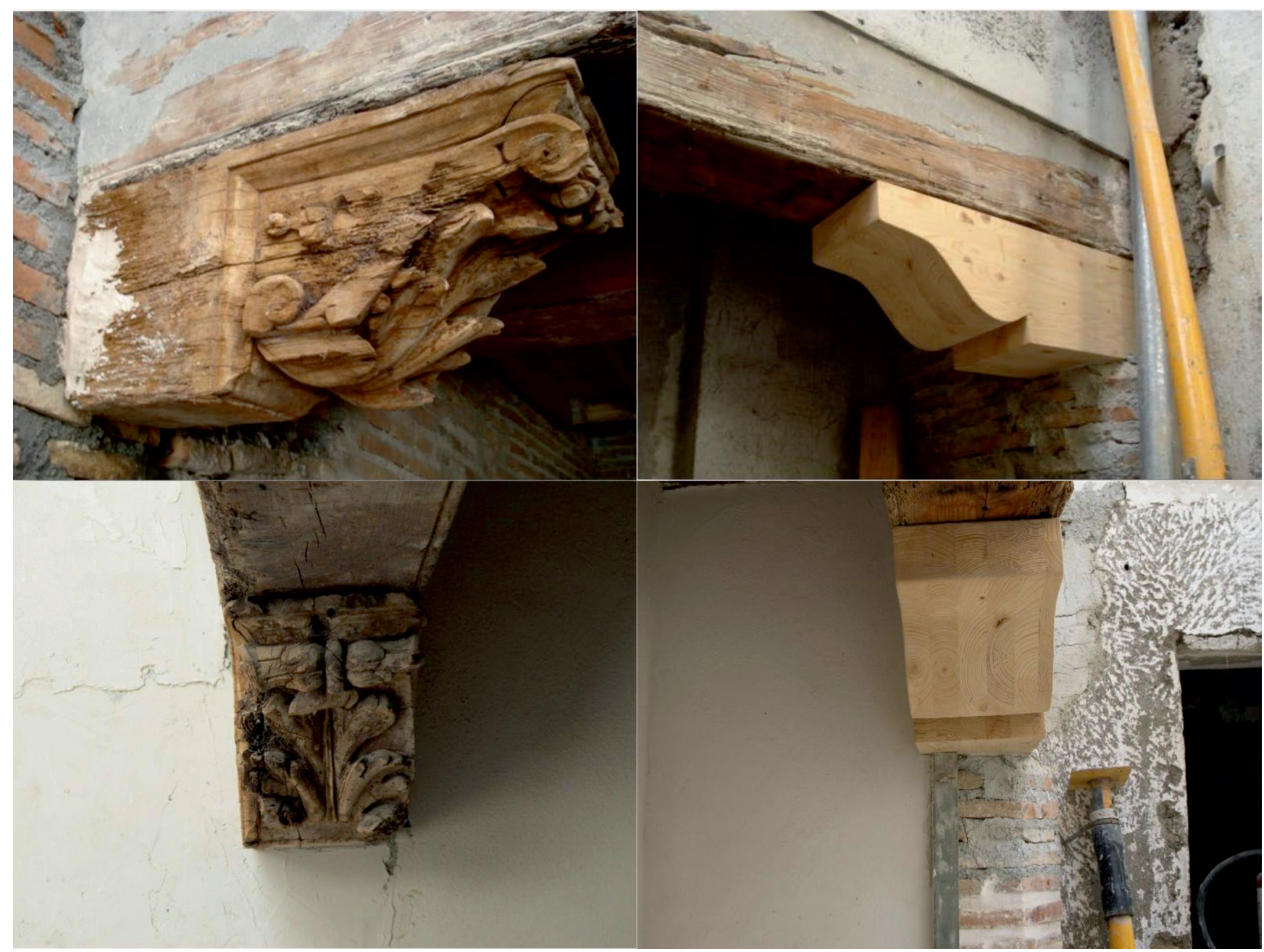

Figura 6. Ejemplos de canes de talla esquemática. Archivo Departamento de Construcciones Arquitectónicas (UGR). 
han adoptado una función de estancia, mientras que en Benalúa 11 se ha mantenido la función de paso pero mejorando la confortabilidad térmica.

b) Lucernarios. La inclusión de lucernarios de vidrio ha hecho del patio una extensión habitacional del inmueble, posibilitado su uso al margen de las condiciones climatológicas y ambientales y favoreciendo en el uso hotelero e institucional el desarrollo de actividades sociales en él.

El uso de todos estos tipos de cerramiento puede suponer la modificación de las condiciones higrotérmicas de los muros, provocando problemas de condensación por la falta de ventilación que se establece -Guinea 19-.

Su correcta disposición será clave para evitar estos problemas. En San Juan de los Reyes 94, las dificultades de colocación por la diferencia de cota a la que se registraba la coronación de los frentes del patio, fueron solventadas porque en el lateral septentrional se situó el lucernario por debajo de la barandilla del mirador, empotrándolo en un perfil metálico, mientras que en el resto se situó sobre el canalón reforzado, lo que impidió una solución estanca y favoreció la traspiración, evitando condensaciones interiores (11).

c) Toldos. Algunos patios han sido cubiertos por toldos practicables aportando confortabilidad. La acción combinada de dos estratos de distinto material favorece su función como aislante térmico. Sus beneficios están basados en sus características materiales, destinando el inferior, de fibra vegetal, a evitar el paso de los rayos solares, mientras que el superior, de fibra plástica impermeable, conduce y evacua las pluviales hasta las canales de la cubierta(10). Estas propuestas las encontramos en los actuales hoteles de Placeta de Peregrinos 1 y Cuesta de la Victoria 9. De mayor simplicidad y de un solo estrato el de Cuesta de Aceituneros 6.

\section{CONCLUSIONES}

El estudio que presentamos, pone de manifiesto como en la franja temporal analizada ha existido una evolución de las intervenciones practicadas sobre las unidades de patio. Aunque ha sido constante la devolución del carácter estético y ambiental en todo el periodo, en un primer estadio las actuaciones han estado más cercanas a restauraciones filológicas, incluso con propuestas que han planteado la recuperación desde un restauro crítico a veces sin una sólida justificación teórica. Sin embargo, en las intervenciones más recientes, se ha tendido hacia un mayor rigor y compromiso con el valor de autenticidad depositado en la tipología, en la materia y en la tecnología constructiva, atendiendo a las particularidades y singularidades de cada caso. Los procesos han estado marcados por la conservación, en la que ha tenido cabida un intervencionismo reconstructivo amparado en necesidades funcionales.

Asimismo, la recuperación se ha enfocado en la puesta en relación con el entorno, al devolver unos valores históricos, arquitectónicos y paisajísticos que han buscado la integración en el contexto urbano del que forma parte y configura su perfil.

La materialidad ha sido modificada y transformada, devolviéndole la dignidad constructiva con propuestas de recuperación de un lenguaje propio con materiales similares y afines, pero sin desestimar los beneficios que ofrece la tecnología contemporánea que adopta un papel colaborante y de diferenciación del momento presente incentivando el equilibrio o el contraste físico y estético.

\section{REFERENCIAS}

(1) López Guzmán, R. (1987). Tradición y clasicismo en la Granada del siglo xvı: Arquitectura civil y urbanismo. Granada: Diputación.

(2) Henares Cuéllar, I., López Guzmán, R. (1989). Arquitectura mudéjar granadina. Granada: Caja General.

(3) López Guzmán, R. (2007). La arquitectura doméstica granadina en los inicios del siglo xvi. En Passini, J., Izquierdo Benito, R. (coords.) La historia medieval de Toledo. Historia, arqueología y rehabilitación de la casa, pp. 17-34. Toledo: Universidad de Castilla-La Mancha.

(4) Orihuela Uzal, A. (2001). La casa andalusí en Granada s. XIII-Xvi. En La casa meridional, pp. 299-314. Sevilla: Junta de Andalucía.

(5) Gómez-Moreno Calera, J. M. (1995). El mudéjar granadino. En Henares Cuéllar, I. (coord.) El mudéjar iberoamericano. Del Islam al Nuevo Mundo, p. 51. Madrid, Lunwerg.

(6) Almagro Gorbea, A., Orihuela Uzal, A. (2001). De la casa andalusí a la casa morisca: La evolución de un tipo arquitectónico. En Passini, J. (coord.) La ciudad medieval: de la casa al tejido urbano, pp. 51-70. Cuenca: Universidad de Castilla-La Mancha.

(7) Orihuela Uzal, A. (1996). Técnicas constructivas en la arquitectura doméstica de los moriscos granadinos. En Actas del I Congreso de Historia de la Construcción, pp. 395-398. Madrid: CEHOPU/CEDEX/MOPT/Instituto Juan de Herrera.

(8) Pica, V. (2013). Dos experiencias de rehabilitación de casas castellanas en el Albaicín de Granada. Cuesta de las Arremangadas, 6 y Cuesta del Perro, 6. Revista e-rph, (12), http://www.revistadepatrimonio.es/revistas/numero12.

(9) Gutiérrez Carrillo, M. a L. (2009). Intervenciones y nuevos usos de la arquitectura doméstica. En López Guzmán, R. (coord.) Arquitectura doméstica en la Granada Moderna, pp. 317-348. Granada: Fundación Albaicín.

(10) Orihuela Uzal, A.(2007). Restauración de casas andalusíes en Granada. En Passini, J. La Historia medieval de Toledo. Historia, arqueología y rehabilitación de la casa. Toledo: Universidad de Castilla-La Mancha.

(11) López Osorio, J. M., Espinar, A. L. (2004). Restauración de una casa morisca en el Albayzín de Granada. Loggia. Arquitectura y Restauración, (16): 84-102. 